\title{
Pulmonary edema post-adenotonsillectomy in children
}

\author{
Elaf Ahmed, MBBS, Nasser K. Almutairi, MBBS.
}

\begin{abstract}

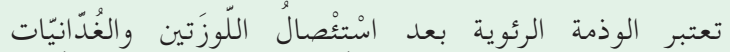

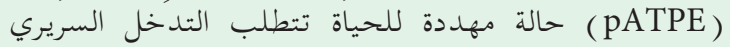

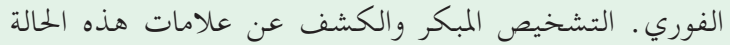

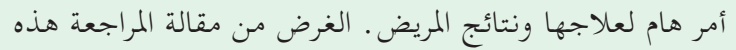

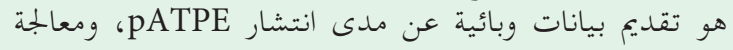

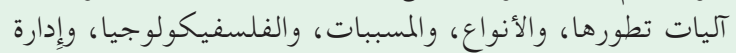

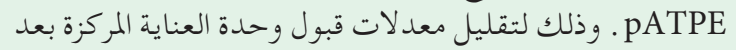

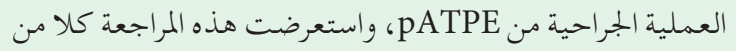

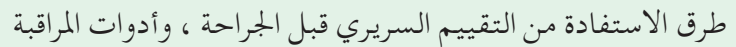
الجراحية/بعد العملية الجراحية، والاحتياطات الإِجرائية.
\end{abstract}

Post-adenotonsillectomy pulmonary edema (pATPE) is a life-threatening condition that necessitates immediate clinical intervention. The early diagnosis and detection of the signs of this condition is vital to its treatment and patient outcome. The purpose of this review article is to present epidemiological data on the prevalence of pATPE, and address the mechanisms of development, types, etiology, pathophysiology, and management of pATPE. In order to minimize postoperative intensive care unit admission rates of pATPE, utilization of preoperative clinical assessment, operative/postoperative monitoring tools, and procedural precautions are discussed.

Saudi Med J 2018; Vol. 39 (6): 551-557 doi: 10.15537/smj.2018.6.21887

From the Department of Otorhinolaryngology, King Saud Medical City, Riyadh, Kingdom of Saudi Arabia.

Address correspondence and reprint request to: Dr. Elaf Ahmed, Department of Otorhinolaryngology, King Saud Medical City, Riyadh, Kingdom of Saudi Arabia. E-mail: dr.elaf1989@gmail.com ORCID ID: orcid.org/0000-0003-2940-1070

Disclosure. Authors have no conflict of interests, and the work was not supported or funded by any drug company.
Cleep disordered breathing (SDB) is a spectrum of $\checkmark$ breathing disorders encompassing primary snoring at one end and obstructive sleep apnea syndrome (OSA) at the other end. While snoring is a primary symptom, OSA is a critical pathological condition that requires medical intervention. ${ }^{1}$ Obstructive sleep apnea is a condition characterized by increased upper airway resistance to air flow and intermittent upper airway closure followed by subsequent hypoxemia, hypercapnia and an interrupted sleep. Polysomnography (PSG) is the gold standard for the diagnosis and assessment of the severity of OSA. In adults, continuous positive air pressure (CPAP) is the mainstay of treatment for OSA according to the mainstream of international societies; ${ }^{2}$ while in children, adenotonsillectomy could be considered as first line treatment of OSA. According to Wiatrak et al, ${ }^{3}$ children whose polysomnographic tests demonstrate an apnea-hypopnea index (AHI) $>10$ /hours or significant oxygen desaturation $<90 \%$ are candidates for surgical intervention. Prevalence of OSA among adults aged $30-70$ years was estimated to be approximately $13 \%$ in males and $6 \%$ in females. ${ }^{4}$ However, local studies of OSA in Saudi adults indicated that $33.3 \%$ of males and $39 \%$ of females are considered to be at high risk of OSA. ${ }^{5,6}$ In pediatrics, one study reports a prevalence of OSA of approximately $4 \%,{ }^{7}$ while other studies estimate $1.2-5.7 \%$ of that population. ${ }^{8,9}$ Generally, studies show an approximate 3-fold increase in behavior and neurocognitive abnormalities in children with sleep-disordered breathing. ${ }^{10}$ The realization of neurocognitive and cardiopulmonary complications associated with recently treated OSA in children promoted awareness of OSA treatment in children. ${ }^{11,12}$

Adenotonsillectomy in pediatric patients has evolved from being a treatment of adenotonsillar hypertrophy and chronic pharyngitis to the management of sleepdisordered breathing. ${ }^{13}$ According to the American Academy of Otolaryngology, Head and Neck Surgery (AAO-HNS), candidates for adenotonsillectomy in the past were patients with 3 or more infections of the tonsils and/or adenoids per year, or had cases of chronic tonsillitis which were unresponsive to 
beta-lactamases. ${ }^{14}$ Currently, however, adenotonsillar hypertrophy has been identified as the most commonlyrecognized anatomic risk factor in pediatric OSA. ${ }^{15}$ Therefore, adenotonsillectomy (AT) is now considered as the first-line treatment for OSA worldwide. ${ }^{10,16}$ Adenotonsillectomy is proven to restore normal PSG in most OSA cases ${ }^{17}$ and consequently improves the quality of life for those patients. Based on the need for cost optimization by third-party medical insurance providers, it became necessary to evaluate "the possibility of performing adenotonsillectomy on an out-patient basis. Such studies revealed "the suitability of performing this procedure with acceptable efficiency as long as good communication between the surgeon, anesthesiologist and the parents of the child is maintained.

Pulmonary edema (PE), although a rare complication of adenotonsillectomy, ${ }^{18}$ is a life-threatening condition that necessitates immediate medical intervention. In the absence of comorbid pulmonary conditions, post-adenotonsillectomy pulmonary edema (pATPE) may be referred to as negative pressure pulmonary edema (NPPE). It is worth mentioning that NPPE can be classified into type I-NPPE and type II-NPPE. ${ }^{19}$ Treatment options for pATPE are similar to those of PE and these include oxygen supplementation, restoration of optimal positive end-expiratory pressure (PEEP), and diuretics.

Cost-containment and reduction are among the major concerns of the health care systems in developing countries. The aim of this study is to perform a cost-benefit analysis of ICU admissions following adenotonsillectomy in OSA patients for fear of developing pulmonary edema. Is it really necessary to admit to the ICU all children with risk factors who underwent adenotonsillectomy to prevent this complication? Additionally, we aim to highlight the probable tools that can reduce rates of ICU admissions among such a cohort.

Etiology/pathophysiology. Post-adenotonsillectomy pulmonary edema may be considered as negative pressure pulmonary edema (NPPE) which has 2 major subclasses. The first is type I-NPPE which results from the forceful expiration against an acutely obstructed upper airway. The second is type II-NPPE which results from the surgical removal of a chronic upper airway obstruction, such as in an OSA patient who underwent adenotonsillectomy. This results in a sudden decrease in intrathoracic pressure precipitating transudation of fluid into the interstitial and alveolar spaces. Reasons for the development of type I-NPPE include accidental occlusion of an endotracheal tube while intubated, ${ }^{20}$ croup and epiglottitis especially in children, ${ }^{21}$ and laryngospasm due to post-extubation. ${ }^{22}$ In addition, administration of muscle relaxants at the beginning of an inhalational induction of anesthesia can induce type I-NPPE due to the premature paralysis of glossal muscles before the diaphragm. ${ }^{23}$ Generally, the symptoms of PE develop immediately, although sometimes the onset may be considerably delayed for a few hours in the postoperative period. Thus, close post-operative observation must be continued for an extended time in patients with risk factors for pATPE. ${ }^{19}$

A couple of widely accepted mechanisms have been published to demonstrate the development of pATPE. One mechanism suggests that chronic upper airway obstruction associated with OSA promotes an elevated level of auto positive end-expiratory pressure (auto-PEEP). Type II-NPPE develops upon sudden relief for chronic upper airway obstruction via adenotonsillectomy (sudden decrease in auto-PEEP), creating a negative intrathoracic pressure $(-50$ to -100 $\mathrm{cmH}_{2} \mathrm{O}$ ). Consequently, venous return to the heart is increased with subsequent elevation of ventricular enddiastolic volume. Thus, the left ventricular end-diastolic pressure is elevated leading to transudation of fluids in the lung interstitium and alveoli causing pulmonary edema. ${ }^{24-26}$ On the other hand, type I-NPPE originates from negative intrathoracic pressure developed from forceful respiration against an acutely-obstructed upper airway. Furthermore, obstruction resulting in hypoxia in both types triggers a massive sympathetic discharge causing a blood shift from the systemic to the pulmonary circulation due to negative intrapulmonary pressure. ${ }^{27}$ Another suggested mechanism states that the chronic mechanical stress developed from respiration against an obstructed upper airway may induce alterations in the alveolar epithelial and pulmonary microvascular membranes, resulting in increased pulmonary capillary permeability, and consequently, protein-rich PE. ${ }^{25,28,29}$

Epidemiology. Post-operative adenotonsillectomy complications may be classified into respiratory and non-respiratory complications. Respiratory complications include persistent oxygen desaturation, laryngospasms, bronchospasms, and pulmonary edema. Generally, post-operative respiratory complications are approaching $6.5 \%$ in children; while children less than 3 years old have a rate of $10 \% .{ }^{30}$ However, pATPE is a rare, life threatening complication that requires immediate intervention. ${ }^{31-33}$

In a study of 86 post-adenotonsillectomy children with a mean age of $5.3 \pm 2.2$ years and without craniofacial anomalies or significant cardiopulmonary comorbidities, cases with apnea-hypopnea index (AHI) $\geq 40$ showed significant statistical correlations with post- 
operative respiratory complications. ${ }^{34}$ Results of the study revealed $11.6 \%$ had respiratory complications, none of which was pulmonary edema. Kon-Tai et a ${ }^{35}$ conducted a study of 610 children aged $<18$ years, mean age $7.2 \pm 3.3$ years, with diverse comorbidities and risk factors. All underwent adenotonsillectomy for the treatment of OSA. Although the study reported complications related to oxygen saturation-related between $1.6 \%$ to $14.3 \%$ with varying severity, only $0.5 \%$ developed pneumonia. The Kon-Tai study revealed a low risk of major respiratory complications (laryngospasm, bronchospasm, pulmonary edema, pneumonia) following adenotonsillectomy in this population. Melissa et $\mathrm{al}^{30}$ reported $6.4 \%$ as prevalence of post-adenotonsillectomy respiratory complications in a study that involved 2315 patients under 6 years. Of this population, $0.7 \%$ developed serious complications including atelectasis, infiltrate, and pulmonary edema. Sofia et $\mathrm{al}^{36}$ documented a $0.45 \%$ prevalence of PE among a study cohort of 221 school-aged children. Nuntiger et $\mathrm{al}^{37}$ also conducted a study involving 216 patients with an average age of 6.6 years and high proportions of comorbidities such as craniofacial abnormalities, obesity, and pulmonary hypertension. In this study, a $4.3 \%$ prevalence of post-operative PE after adenotonsillectomy was reported. Guinard referred to Type I-NPPE that develops due to laryngospasm after airway surgery as laryngospasm-induced pulmonary edema. ${ }^{27}$ The Australian Incident Monitoring Study of 4000 incidents of laryngospasm during anesthesia showed that NPPE occurs in up to $4 \%$ of all incident reports of laryngospasm. ${ }^{38}$ The previous high ratios could be attributed to the wide inclusion criteria of the study regarding comorbidities and type of surgical procedure.

Risk factors for development of $p A T P E$. Development of pulmonary edema after adenotonsillectomy is life threatening condition; however, it is uncommon complication. Young age ( $<3$ years) or the presence of some comorbid conditions such as asthma, history of prematurity and craniofacial malformations may increase the risk of developing PE in children undergoing adenotonsillectomy. ${ }^{30}$

Asthma is one of the risk factors for the development of PE after adenotonsillectomy, as it predisposes pulmonary capillary epithelium to disruption either directly due to high breathing workload, or indirectly by cytotoxic proteins derived from the migration of inflammatory cells. Regarding etiological mechanisms, a pathophysiological cascade due to any of these mechanisms leads to an extravasation of proteins from post-capillary venules into interstitial tissues resulting in the development of PE. ${ }^{39-41}$

Premature infants with respiratory distress syndrome (RDS) who were ventilated at birth commonly have a condition known as chronic lung disease (CLD) of prematurity. From a histological point of view, Hulsmann R. and Van Anker ${ }^{42}$ stated that the evolution of CLD can be divided into an early inflammatory phase followed by a subacute and chronic fibroproliferative phase. An influx of inflammatory cells and increased levels of cytokines in alveolar sacs characterize the first phase, while the second phase is characterized by hyperplasia of type II pneumocytes, and interstitial and perialveolar fibrosis. Surviving patients show persistent lung function abnormalities. Therefore CLD is considered a risk factor for pATPE due to abnormalities of alveolar wall.

Alida et $\mathrm{al}^{43}$ reported that $95 \%$ of infants with Down syndrome who were referred for PSG had OSA, out of which $75 \%$ had severe OSA, which qualified them as candidates for adenotonsillectomy. Bronchial asthma, Down syndrome, and other craniofacial conditions may precipitate high auto-PEEP, which upon sudden relief via adenotonsillectomy result in the development of pATPE. ${ }^{44}$

Management. As a subtype of pulmonary edema, pATPE is usually self-limited and easily corrected. ${ }^{45}$ Supportive therapy in these patients begins with close observation in an ICU or step-down unit that has high surveillance. Strategies for correction of pATPE include maintenance of airway via intubation. If the airway is obstructed due to the patient biting down on the endotracheal tube, a dose of succinylcholine (0.1-0.2 $\mathrm{mg} / \mathrm{kg})$ may be given to relax the jaw muscles. ${ }^{19}$ Invasive or non-invasive supplemental oxygen to restore appropriate PEEP via continuous positive airway pressure (CPAP) or bi-level positive airway pressure (BPAP) should be provided. Generally, diuretics may be administered to correct fluid accumulation in lung interstitial spaces and alveoli, unless the patient is hypovolemic. In severe cases of pATPE, mechanical ventilation may be required. It is worth mentioning that non-invasive respiratory support via CPAP or BPAP decreases the work of breathing, improves alveolar gas exchange, reduces left ventricular preload and afterload, increases cardiac output and improves hemodynamics. ${ }^{19}$ Evidence suggests that noninvasive respiratory support may be an effective strategy to reduce intubation rates, ${ }^{46,47}$ as well as ICU and hospital lengths of stay ${ }^{46}$ in postoperative patients. ${ }^{19}$

Perioperative measures to minimize the probability of $P A T P E$ and ICU admission rates. Generally, 
adenotonsillectomy is an out-patient procedure; the patient may be discharged on the same day after procedure regardless the surgical technique utilized. However, in some situations it is recommended to hospitalize patient for few hours to a few days based on clinical evaluation and the presence of comorbid conditions. ${ }^{30}$ Specifically, children at risk for upper airway obstruction or respiratory compromise following tonsil and adenoid surgery such as those under the age of 3, or who have comorbidities like neurological problems, congenital heart disease, prematurity, Down syndrome or craniofacial abnormalities are candidates for post-adenotonsillectomy admission. It has been found that $80 \%$ of pulmonary edema occurs within minutes after relief of upper airway obstruction. ${ }^{48}$
Edema ranges from mild to severe depending on the degree of obstruction and pulmonary capillary injury. ${ }^{45}$ Cost reduction is a worldwide trend in the health care system. This current work involves a cost/ benefit assessment of OSA patients who underwent adenotonsillectomy and were admitted to the ICU as a precaution for the possibility of developing pulmonary edema. Patient variation and waste associated with the delivery of care is a major factor that contributes to the escalation of healthcare costs. In order to minimize ICU admission rates, it is necessary to analyze the root causes leading to ICU admissions. In this context, the optimum management of healthcare resources requires, first of all, the assessment of the cluster of patients with OSA who require in-patient admission. Secondly, it is

Table 1 - Summary of the Articles which were Reviewed.

\begin{tabular}{|c|c|c|c|c|c|}
\hline Author's name & References & $\begin{array}{l}\text { Type of } \\
\text { study }\end{array}$ & Year & $\begin{array}{c}\text { No. of } \\
\text { patients }\end{array}$ & Results \\
\hline David Kasle & 34 & Case Series & 2016 & 86 & $\begin{array}{l}\text { Eighty-six patients (mean age } 5.3 \pm 2.2 \text { years) were included. There was a } \\
\text { statistically significant }(p=0.03) \text { relationship between an apnea-hypopnea index } \\
\geq 40 \text { (AHI40) and post-operative respiratory complications. Apnea-hypopnea index } \\
40 \text { also had the greatest magnitude of association with postoperative respiratory } \\
\text { complications }(\mathrm{OR}=5.313) \text {. An AHI } \geq 25 \text { (AHI25) was marginally significant } \\
(p=0.067) \text {. No significant difference in outcome occurrence was found when } \\
\text { analyzing rates of complication in patients with BMI above and below } 18(p=0.20) \\
\text { or oxygen }\left(\mathrm{O}_{2}\right) \text { nadir above and below } 80 \%(p=0.09) \text {. The AHI ranged from } 0 \text { to } \\
112.2 \text {, and no postoperative respiratory complications were identified in children } \\
\text { with an AHI less than } 10 \text {. }\end{array}$ \\
\hline
\end{tabular}

\begin{tabular}{|c|c|c|c|c|c|}
\hline Nuntigar Sonsuwan & 37 & Retrospective & 2014 & 216 & $\begin{array}{l}\text { There were } 216 \text { patients who underwent adenotonsillectomy due to airway } \\
\text { obstruction during the study period. Five patients were excluded due to incomplete } \\
\text { data. Of those included, } 129 \text { patients }(61.1 \%) \text { were male with mean age of } 6.6 \\
\text { (SD 3.2) years. Four significant factors associated with the development of post- } \\
\text { operative pulmonary edema after the adenotonsillectomy were procedure, age, } \\
\text { obesity, and pulmonary hypertension. }\end{array}$ \\
\hline Peppard et al & 4 & Cohort study & 2013 & 1520 & $\begin{array}{l}\text { The prevalence estimates of moderate to severe sleep-disordered breathing (AHI, } \\
\text { measured as events/hour, } \geq 15) \text { are } 10 \%(95 \% \text { confidence interval }[\mathrm{CI}]: 7,12) \\
\text { among } 30-49 \text { year-old men; } 17 \%(95 \% \mathrm{CI}: 15,21) \text { among } 50-70 \text { year-old men; } \\
3 \% \text { (95\% CI: } 2 \text {, 4) among } 30-49 \text { year-old women; and } 9 \%(95 \% \mathrm{CI}: 7,11) \text { among } \\
50-70 \text { year-old women. These estimated prevalence rates represent substantial } \\
\text { increases over the last } 2 \text { decades (relative increases of between } 14 \% \text { and } 55 \% \\
\text { depending on the subgroup). }\end{array}$ \\
\hline BaHammam et al & 6 & $\begin{array}{l}\text { Cross- } \\
\text { sectional } \\
\text { study }\end{array}$ & 2008 & 578 & $\begin{array}{l}\text { Five hundred and seventy-eight middle-aged Saudi males with a mean age of } 45.02 \\
\pm 9.3 \text { year were surveyed in this study. Snoring was present in } 52.3 \% \text {, and breathing } \\
\text { pauses more than once per week was noticed in } 11.3 \% \text {. Based on the Berlin } \\
\text { questionnaire stratification for risk of obstructive sleep apnea syndrome (OSA), } \\
33.3 \% \text { were considered as high risk patients for OSA. The occurrence of daytime } \\
\text { tiredness more than once/week was reported by } 35.5 \% \text {. The prevalence of snoring } \\
\text { and risk for OSA is similar to that reported in the US. }\end{array}$ \\
\hline Bixler et al & 9 & $\begin{array}{l}\text { Phase I cross } \\
\text { sectional } \\
\text { study } \\
\text { Phase II } \\
\text { clinical study }\end{array}$ & 2009 & 5740 & $\begin{array}{l}\text { Each child was assessed with a full polysomnogram and completed a history/ } \\
\text { physical examination including an electrocardiogram, otolaryngology examination, } \\
\text { and pulmonary evaluation. The prevalence of moderate sleep disordered breathing } \\
\text { (SDB) (apnea-hypopnea index } \geq 5 \text { ) was } 1.2 \% \text {. The independent risk factors } \\
\text { included nasal abnormalities and minority associated only with mild }(1<\mathrm{AHI}<5) \\
\text { SDB and snoring and waist circumference associated with all levels of SDB. Tonsil } \\
\text { size, based on visual inspection, was not an independent risk factor. }\end{array}$ \\
\hline Thomas et al & 33 & Case report & 1999 & 1 & $\begin{array}{l}\text { The rapidity of onset of negative pressure pulmonary edema may lead to death if } \\
\text { the disease is not recognized thus it must be emphasized that this disease can occur } \\
\text { in any patient especially in patients with obstructive process of upper airway. }\end{array}$ \\
\hline
\end{tabular}


important to highlight the tools and precautions that can reduce rates of ICU admission even among such a risky group (Table 1).

Preoperative clinical assessment. A pre-operative clinical assessment of patients could dramatically help rule out children with comorbid risk factors, generally decreasing the rate of post-operative ICU admissions. It is important to mention the controversial criteria of the American Academy of Otolaryngology (AAO) and American Academy of Pediatrics (AAP) which recommend overnight monitoring of all OSA patients with $\mathrm{AHI} \geq 10$ (by the AAO) and AHI $\geq 24$ (by the AAP) following an adenotonsillectomy. As discussed in the next section, simple monitoring of pulse oximetry could empirically help solve such controversies surrounding the potential development of PE. Specifically, the next few paragraphs will focus on children who do have risk factors for development of pATPE.

Operative/postoperative monitoring tools. With prompt diagnosis and intervention, most pATPE patients can be treated without complications. Since PE develops in a matter of minutes after adenotonsillectomy, simply monitoring the oxygen saturation in the operating room and post-anesthesia care unit using pulse oximetry usually identifies patients at risk and in need of in-patient hospitalization rather than ICU admission. This is because signs and symptoms in most cases are subtle. ${ }^{45}$ On the other hand, in the absence of pulse oximetry, in-patient admission of patients with OSA could be limited to patients who have risk factors for the development of pATPE. Such patients include children younger than 3 years old, patients with severe OSA, those with comorbid conditions including asthma, obesity, cardiac involvement (right ventricular hypertrophy), Down syndrome, history of prematurity, craniofacial abnormalities, neuromuscular diseases, chronic lung disease, and sickle cell disease. ${ }^{49-55}$

In conclusion, a combination of pulse oximetry monitoring and clinical evaluation of patients can effectively identify cases in need of in-patient monitoring. Since the management of pATPE ranges from simple oxygen supplementation, application of noninvasive positive airway pressure up to diuretic therapy, advent of inexpensive portable versions of pulse oximeters allow close patient monitoring for pATPE development in sub-ICU level care units, stepping up and down to ICU or normal ward care according to case progression. Primarily, patients with risk factors may be admitted to sub-ICU level care units provided there are no signs of oxygen desaturation and other vital signs. Such simple surveillance could dramatically reduce the cost of healthcare services. Intensive care unit admissions should be limited to cases that require multiple-organ support or advanced respiratory support such as severe $\mathrm{PE}$ in which pulmonary venous pressure exceeds $30 \mathrm{~mm} \mathrm{Hg}^{56}$ and which requires invasive mechanical ventilation/CPAP/BPAP via trans-laryngeal tracheal or tracheostomy.

Procedural "Surgical-anesthetical" precautions. Several surgical techniques have been developed over the years, but the core principles remain unchanged. The achievement of successful surgery starts with induction of anesthesia, patient positioning for oral intubation, and the surgical dissection technique. Extracapsular techniques include sharp dissection, monopolar electrocautery, bipolar cautery and harmonic scalpel, while intracapsular techniques include microdebrider, bipolar radiofrequency ablation, or carbon dioxide laser. ${ }^{57}$

Mechanical stimulation of the endotracheal tube during extubation often results in laryngospasm which may induce type I-NPPE. Therefore, patient intubation should be carried out either under deep anesthesia or after muscle relaxant administration to lower the incidence of laryngospasms. Redundant controversies exist among anesthesiologists regarding which technique of tracheal extubation (awake versus anesthetized), is better at reducing the incidence of laryngospasms. ${ }^{58}$ With regards to this, Lee recommended extubation while the lungs are inflated by positive pressure. ${ }^{59}$ There is a close association between the type of surgery performed and the occurrence of laryngospasm. Tonsillectomy and adenoidectomy are associated with the highest incidence of laryngospasm (21-26\%)..$^{58,60}$ However, induction of anesthesia in pediatrics either intravenously or by inhalation, using suitable anesthetic drugs is a controversial topic that should be addressed on a case by case basis. Intravenous anesthesia was found to be associated with a lower incidence of laryngospasm than inhalational anesthesia. ${ }^{61}$ Despite extensive debate regarding the avoidance of laryngospasm, several strategies have been suggested to lower the incidence of laryngospasm. Koc et $\mathrm{al}^{62}$ reported that topical lignocaine $2 \%$ at a dose of $4 \mathrm{mg} / \mathrm{kg}$ sprayed on the glottis, or $2 \%$ intravenous lignocaine given at $1 \mathrm{mg} / \mathrm{kg}$ five minutes before extubation are fairly effective in preventing laryngospasm following adenotonsillectomy. According to Gulhas et al, ${ }^{63} 15 \mathrm{mg} / \mathrm{kg}$ magnesium sulfate in $30 \mathrm{ml}$ $0.9 \% \mathrm{NaCl}$ administered over 20 minutes after tracheal intubation has also been suggested to reduce the incidence of laryngospasm post-adenotonsillectomy. Intravenous administration of $0.25-0.5 \mathrm{mg} / \mathrm{kg}$ propofol prior to extubation has also been shown to be effective. ${ }^{58}$ 
Some anesthesiologists indicated that inhalation of 5\% carbon dioxide could prevent laryngospasm, since respiratory drive to exhale the carbon dioxide overrides the laryngospasm reflex.

In conclusion, pATPE is a rare but life-threatening complication that requires immediate intervention. Young age ( $<3$ years) or the presence of some comorbid conditions such as asthma, history of prematurity, craniofacial malformations, Down syndrome and severe OSA may increase the risk of developing PE in children undergoing adenotonsillectomy. With prompt diagnosis and intervention, most pATPE patients can be treated without incident. Since PE develops in a matter of minutes after adenotonsillectomy, simply monitoring oxygen saturation using pulse oximetry in the operating room and in the post-anesthesia care unit usually identifies patients at risk and in need of in-patient hospitalization rather than ICU admission.

\section{References}

1. Lipton AJ, Gozal D. Treatment of obstructive sleep apnea in children: do we really know how? Sleep Med Rev 2003; 7: 61-80.

2. Epstein LJ, Kristo D, Strollo PJ Jr, Friedman N, Malhotra A, Patil SP, et al. Clinical guideline for the evaluation, management and long-term care of obstructive sleep apnea in adults. J Clin Sleep Med 2009; 5: 263-276.

3. Wiatrak BJ, Woolley AL. Pharyngitis and adenotonsillar disease. Otolaryngology Head and Neck Surgery 2005; 3: 188-215.

4. Peppard PE, Young T, Barnet JH, Palta M, Hagen EW, Hla KM. Increased prevalence of sleep-disordered breathing in adults. Am J Epidemiol 2013; 177: 1006-1014.

5. BaHammam AS, Alrajeh MS, Al-Jahdali HH, BinSaeed AA. Prevalence of symptoms and risk of sleep apnea in middle-aged Saudi males in primary care. Saudi Med J 2008; 29: 423-426.

6. BaHammam AS, Al-Rajeh MS, Al-Ibrahim FS, Arafah MA, Sharif MM. Prevalence of symptoms and risk of sleep apnea in middle-aged Saudi women in primary care. Saudi Med J 2009; 30: 1572-1576.

7. Lumeng JC, Chervin RD. Epidemiology of pediatric obstructive sleep apnea. Proc Am Thorac Soc 2008; 5: 242-252.

8. Li AM, So HK, Au CT, Ho C, Lau J, Ng SK, et al. Epidemiology of obstructive sleep apnoea syndrome in Chinese children: a two-phase community study. Thorax 2010; 65: 991-997.

9. Bixler EO, Vgontzas AN, Lin H-M, Liao D, Calhoun S, Vela-Bueno A, et al. Sleep disordered breathing in children in a general population sample: prevalence and risk factors. Sleep 2009; 32: 731-736.

10. Schechter MS. Technical report: diagnosis and management of childhood obstructive sleep apnea syndrome. Pediatrics 2002; 109: e69-e69.

11. Amin R, Somers VK, McConnell K, Willging P, Myer C, Sherman $\mathrm{M}$, et al. Activity-adjusted 24-hour ambulatory blood pressure and cardiac remodeling in children with sleep disordered breathing. Hypertension 2008; 51: 84-91.
12. Kaditis AG, Chaidas K, Alexopoulos EI, Varlami V, Malakasioti $\mathrm{G}$, Gourgoulianis K. Effects of adenotonsillectomy on R-R interval and brain natriuretic peptide levels in children with sleep apnea: a preliminary report. Sleep Med 2011; 12: 646-651.

13. Rothschild MA, Catalano P, Biller HF. Ambulatory pediatric tonsillectomy and the identification of high-risk subgroups. Otolaryngology-Head and Neck Surgery 1994; 110: 203-210.

14. Smith SL, Pereira KD. Tonsillectomy in Children. ORL J Otorhinolaryngol Relat Spec 2007; 69: 336-339.

15. Baugh RF, Archer SM, Mitchell RB, Rosenfeld RM, Amin R, Burns JJ, et al. Clinical practice guideline: tonsillectomy in children. ORL J Otorhinolaryngol Relat Spec 2011; 144 (1 Suppl): S1-S30.

16. Carroll JL. Obstructive sleep-disordered breathing in children: new controversies, new directions. Clinics in Chest Medicine 2003; 24: 261-282.

17. Brietzke SE, Gallagher D. The effectiveness of tonsillectomy and adenoidectomy in the treatment of pediatric obstructive sleep apnea/hypopnea syndrome: a meta-analysis. Otolaryngol Head Neck Surg 2006; 134: 979-984.

18. da Silva PSL, Neto HM, Andrade MMT, de Mattos Neves CV. Negative-pressure pulmonary edema: a rare complication of upper airway obstruction in children. Pediatric Emergency Care 2005; 21: 751-754.

19. Bhaskar B, Fraser J. Negative pressure pulmonary edema revisited: Pathophysiology and review of management. Saudi J Anaesth 2011; 5: 308.

20. Liu E, Yih P. Negative pressure pulmonary oedema caused by biting and endotracheal tube occlusion--a case for oropharyngeal airways. Singapore Med J 1999; 40: 174-175.

21. Bonadio WA, Losek JD. The characteristics of children with epiglottitis who develop the complication of pulmonary edema. Arch Otolaryngol Head Neck Surg 1991; 117: 205-207.

22. Mehta VM, Har-El G, Goldstein NA. Postobstructive pulmonary edema after laryngospasm in the otolaryngology patient. Laryngoscope 2006; 116: 1693-1696.

23. Warner LO, Martino JD, Davidson PJ, Beach TP. Negative pressure pulmonary oedema: A potential hazard of muscle relaxants in awake infants. Can J Anaesth 1990; 37: 580-583.

24. Capitanio MA, Kirkpatrick JA. Obstructions of the Upper Airway in Children as Reflected on the Chest Radiograph 1. Radiology 1973; 107: 159-161.

25. Kollef $\mathrm{MH}$, Pluss J. Noncardiogenic pulmonary edema following upper airway obstruction 7 cases and a review of the literature. Medicine 1991; 70: 91-98.

26. Randall DA, Hoffer ME. Complications of tonsillectomy and adenoidectomy. Otolaryngology-Head and Neck Surgery 1998; 118: 61-68.

27. Guinard JP. Laryngospasm-induced pulmonary edema. International Journal of Pediatric Otorhinolaryngology 1990; 20: 163-168.

28. Cook CD, Mead J. Maximum and minimum airway pressures at various lung volumes in normal children and adults. Fed Proc 1960; 19: 377.

29. Koh MS, Hsu AAL, Eng P. Negative pressure pulmonary oedema in the medical intensive care unit. Intensive Care Med 2003; 29: 1601-1604.

30. Statham MM, Elluru RG, Buncher R, Kalra M. Adenotonsillectomy for obstructive sleep apnea syndrome in young children: prevalence of pulmonary complications. Arch Otolaryngol Head Neck Surg 2006; 132: 476-480. 
31. McGowan FX, Kenna MA, Fleming JA, O’Connor T. Adenotonsillectomy for upper airway obstruction carries increased risk in children with a history of prematurity. Pediatr Pulmonol 1992; 13: 222-226.

32. Van Kooy MA, Gargiulo RF. Postobstructive pulmonary edema. Am Fam Physician 2000; 62: 401-404.

33. Thomas CL, Palmer TJ, Shipley P. Negative pressure pulmonary edema after a tonsillectomy and adenoidectomy in a pediatric patient: case report and review. AANA J 1999; 67: 425-430.

34. Kasle D, Virbalas J, Bent JP, Cheng J. Tonsillectomies and respiratory complications in children: A look at pre-op polysomnography risk factors and post-op admissions. Int J Pediatr Otorhinolaryngol 2016; 88: 224-227.

35. Kang KT, Chang IS, Tseng CC, Weng WC, Hsiao TY, Lee PL, et al. Impacts of disease severity on postoperative complications in children with sleep-disordered breathing: Postoperative complications in children with SDB. The Laryngoscope [Internet]. [Updated 2017 February; cited 2017 June 18]. Available from: http://doi.wiley.com/10.1002/lary.26539

36. Konstantinopoulou S, Gallagher P, Elden L, Garetz SL, Mitchell $\mathrm{RB}$, Redline S, et al. Complications of adenotonsillectomy for obstructive sleep apnea in school-aged children. Int J Pediatr Otorhinolaryngol 2015; 79: 240-245.

37. Sonsuwan N, Pornlert A, Sawanyawisuth K. Risk factors for acute pulmonary edema after adenotonsillectomy in children. Auris Nasus Larynx 2014; 41: 373-375.

38. Dicpinigaitis P, Mehta D. Postobstructive pulmonary edema induced by endotracheal tube occlusion. Intensive Care Med 1995; 21: 1048-1050.

39. Chung K, Rogers D, Barnes P, Evans T. The role of increased airway microvascular permeability and plasma exudation in asthma. Eur Respir J 1990; 3: 329-337.

40. Jones VC, Birrell MA, Maher SA, Griffiths M, Grace M, O'donnell VB, et al. Role of Ep2 and Ep4 receptors in airway microvascular leak induced by prostaglandin E2. Br J Pharmacol 2016; 173: 992-1004.

41. Khor Y, Teoh A, Lam S, Mo D, Weston S, Reid D, et al. Increased vascular permeability precedes cellular inflammation as asthma control deteriorates. Clin Exp Allergy 2009; 39: 1659-1667.

42. Hulsmann A, Van den Anker J. Evolution and natural history of chronic lung disease of prematurity. Monaldi Arch Chest Dis 1997; 52: 272-277.

43. Goffinski A, Stanley MA, Shepherd N, Duvall N, Jenkinson $\mathrm{SB}$, Davis C, et al. Obstructive sleep apnea in young infants with Down syndrome evaluated in a Down syndrome specialty clinic. American Journal of Medical Genetics Part A 2015; 167: 324-330.

44. Rasheed A, Palaria U, Rani D, Sharma S. A case of negative pressure pulmonary edema in an asthmatic patient after laparoscopic cholecystectomy. Anesth Essays Res 2014; 8: 86-88.

46. Pelosi P, Jaber S. Noninvasive respiratory support in the perioperative period. Curr Opin Anaesthesiol 2010; 23: 233-238.

47. Jaber S, Chanques G, Jung B. Postoperative noninvasive ventilation. The Journal of the American Society of Anesthesiologists 2010; 112: 453-461.
48. Lang SA, Duncan PG, Shephard DA, Ha HC. Pulmonary oedema associated with airway obstruction. Can J Anaesth 1990; 37: 210-8.

49. Patino M, Sadhasivam S, Mahmoud M. Obstructive sleep apnoea in children: perioperative considerations. Br J Anaesth 2013; 111 Suppl 1: i83-i95.

50. Wolfe RM, Pomerantz J, Miller DE, Weiss-Coleman R, Solomonides T. Obstructive Sleep Apnea: Preoperative Screening and Postoperative Care. J Am Board Fam Med 2016; 29: 263-275.

51. Kalra M, Buncher R, Amin RS. Asthma as a risk factor for respiratory complications after adenotonsillectomy in children with obstructive breathing during sleep. Annals of Allergy, Asthma \& Immunology 2005; 94: 549-552.

52. Biavati MJ, Manning SC, Phillips DL. Predictive factors for respiratory complications after tonsillectomy and adenoidectomy in children. Arch Otolaryngol Head Neck Surg 1997; 123: 517-521.

53. McColley SA, April MM, Carroll JL, Naclerio RM, Loughlin GM. Respiratory compromise after adenotonsillectomy in children with obstructive sleep apnea. Archives of Otolaryngology-Head \& Neck Surgery 1992; 118: 940-943.

54. Rosen GM, Muckle RP, Goding GS, Mahowald MW, Ullevig C. Postoperative respiratory compromise in children with obstructive sleep apnea syndrome: can it be anticipated? Pediatrics 1994; 93: 784-788.

55. Ross AT, Kazahaya K, Tom LW. Revisiting outpatient tonsillectomy in young children. Otolaryngol Head Neck Surg 2003; 128: 326-331.

56. Khan AN, Al-Jahdali H, Sarah A-G, Gouda A. Reading chest radiographs in the critically ill (Part II): Radiography of lung pathologies common in the ICU patient. Ann Thorac Med 2009; 4: 149-157.

57. Aremu S. A Review of Tonsillectomy Techniques and Technologies. In: Gendeh BS, editors. Otolaryngology. Croatia: InTech; 2012.

58. Alalami AA, Ayoub CM, Baraka AS. Laryngospasm: review of different prevention and treatment modalities. Paediatr Anaesth 2008; 18: 281-288.

59. Landsman IS. Mechanisms and treatment of laryngospasm. Int Anesthesiol Clin 1997; 35: 67-73.

60. Strauss L. Anaesthetic management of paediatric adenotonsillectomy: anaesthetic supplement. South African Family Practice 2012; 54: 17-20.

61. Al-alami AA, Zestos MM, Baraka AS. Pediatric laryngospasm: prevention and treatment. Curr Opin Anaesthesiol 2009; 22: 388-395.

62. Koc C, Kocaman F, Aygenc E, ÖZDEM C, Cekic A. The use of preoperative lidocaine to prevent stridor and laryngospasm after tonsillectomy and adenoidectomy. Otolaryngology-Head and Neck Surgery 1998; 118: 880-882.

63. Gulhas N, Durmus M, Demirbilek S, Togal T, Ozturk E, Ersoy MO. The use of magnesium to prevent laryngospasm after tonsillectomy and adenoidectomy: a preliminary study. Paediatr Anaesth 2003; 13: 43-47. 